\title{
Can Bipolar Vaporization be Considered an Alternative Energy Source in the Endoscopic Treatment of Urethral Strictures and Bladder Neck Contracture?
}

\author{
Erem K. Basok, Adnan Basaran, Cenk Gurbuz, Asif Yildirim, Resit Tokuc \\ Department of Urology, S.B. Istanbul Goztepe Training and Research Hospital, Istanbul, Turkey
}

\begin{abstract}
Objective: We evaluated the outcome of bipolar energy by using PlasmaKinetic ${ }^{\mathrm{TM}}$ cystoscope instruments in the treatment of urethral stricture and bladder neck contracture.

Materials and Methods: Twenty-two male patients with urethral stricture and five with bladder neck contracture were treated by endoscopic bipolar vaporization. The most common etiology for stricture formation was iatrogenic ( $85.2 \%)$ and the mean stricture length was $12.2 \mathrm{~mm}$. All patients were evaluated with urethrography and uroflowmetry one month and 3 months after surgery. Urethroscopy was routinely performed at the end of the first year. Preoperative mean maximum flow rate (Q max) was $4.9 \mathrm{~mL} / \mathrm{s}$ for urethral stricture and mean $\mathrm{Q}$ max was $3.4 \mathrm{~mL} / \mathrm{s}$ for bladder neck contracture. The results were considered as "successful" in patients where re-stenosis was not identified with both urethrography and urethroscopy. Minimum follow-up was 13.8 months (range 12 to 20).

Results: Tissue removal was rapid, bleeding was negligible and excellent visualization was maintained throughout the vaporization of the fibrotic tissue. Postoperative mean Q max was $14.9 \mathrm{~mL} / \mathrm{s}$ and the success rate was $77.3 \%$ for urethral stricture at mean follow-up time of 14.2 months. The success rate was $60 \%$ with a mean follow-up time of 12.2 months for bladder neck contracture and the mean Q max was $16.2 \mathrm{~mL} / \mathrm{s}$, postoperatively.

Conclusions: The study suggests that bipolar vaporization is a safe, inexpensive and reliable procedure with good results, minimal surgical morbidity, negligible blood loss, and thus, it could be considered as a new therapeutic option for the endoscopic treatment of urethral stricture and bladder neck contracture.
\end{abstract}

Key words: urethra; urethral stricture; endoscopy; vaporization; bipolar energy

Int Braz J Urol. 2008; 34: 577-86

\section{INTRODUCTION}

The management of urethral stricture and bladder neck contracture include periodic dilatation, blind internal urethrotomy, optical urethrotomy with or without monopolar electrocautery or various laser treatment and definitive open urethroplasty. Although long term results of open urethroplasty surgery are excellent, open urethroplasty surgery can be challenging and timeconsuming.
A recent survey of stricture management in the United States showed that most urologists $(57.8 \%)$ do not perform urethroplasty, while 31\% to $33 \%$ would continue to manage the stricture by minimally invasive means despite predictable failure. Many urologists have selected the use of endoscopic procedure as primary approach, but, currently, this approach is no longer justified based on studies reported in the literature (1-3).

Although internal urethrotomy continues to be the most commonly used procedure, the optimal 
management is still widely debated, because the recurrence rates range between $75 \%$ and $80 \%$ in the long term (1-3). As an alternative energy source, the first bipolar device for endourological procedures was Gyrus device using PlasmaKinetic ${ }^{\mathrm{TM}}$ Endourology System (Gyrus PlasmaKinetic ${ }^{\text {TM }}$ System, Medical, Maple Grove, MD). Bipolar energy enables an instant incision and vaporization of the stricture, and contributes to decreased recurrent scar tissue formation (4-6). Thus, current prospective pilot study was conducted to evaluate efficacy and safety of PlasmaKinetic ${ }^{\mathrm{TM}}$ cystoscope instruments in the treatment of urethral strictures and bladder neck contractures.

\section{MATERIALS AND METHODS}

Between May 2004 and December 2005, twenty-seven male patients 29 to 74 years old (mean age 56.3) with urethral strictures or bladder neck contractures underwent endoscopic bipolar vaporization using PlasmaKinetic ${ }^{\mathrm{TM}}$ cystoscope instruments:
Plasma-Cise ${ }^{\mathrm{TM}}$ and Plasma-Cut ${ }^{\mathrm{TM}}$ (Figure-1). The study was performed in accordance with the Helsinki Declaration of the World Medical Association, and written informed institutional research consent was obtained from all patients. The strictures were localized in the urethra and the bladder neck in 22 and 5 patients, and treated with Plasma-Cise ${ }^{\mathrm{TM}}$ and Plasma-Cut ${ }^{\mathrm{TM}}$ in 16 and 11 patients, respectively. The most common cause of stricture was iatrogenic $(85.2 \%)$, followed by trauma (14.8\%). The location of the stricture was penile, bulbar and membranous urethra in 4, 15 and 3 patients, respectively (Table-1). Four of bladder neck contractures were detected after radical retropubic prostatectomy and one after ileal neobladder.

The stricture length was measured by both uroradiography and urethroscopy using a ureteric catheter after excising the scar tissue. The average length of the strictures was $12.2 \mathrm{~mm}$. (range 10 to 25 $\mathrm{mm})$. Twenty-two patients had untreated strictures and the remaining were previously treated by cold-knife urethrotomy in three and urethroplasty in two. There was single stricture in 23 and multiple in 4 patients.
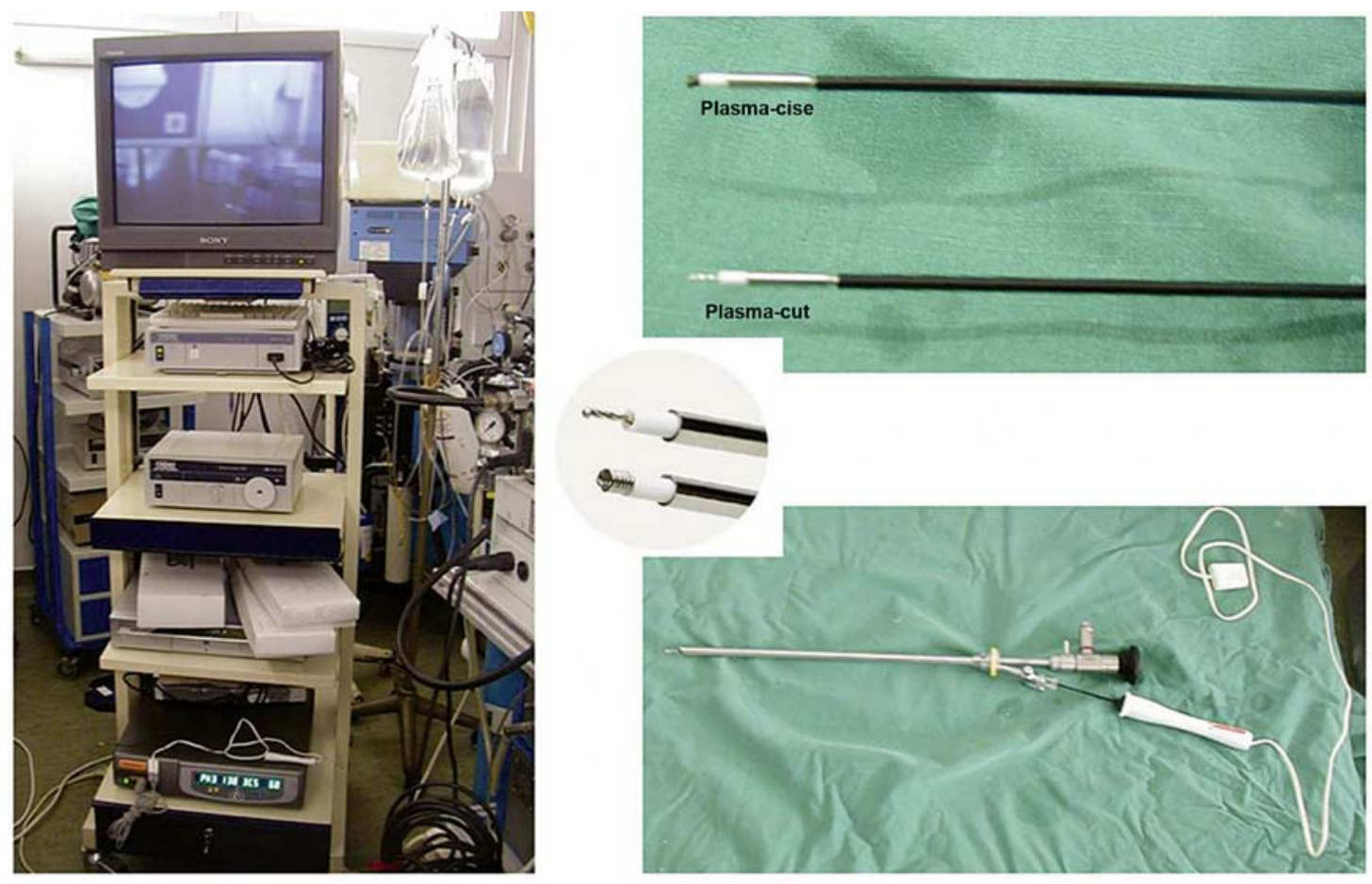

Figure 1 - Gyrus PlasmaKinetic ${ }^{\mathrm{TM}}$ Endourology System and cystoscope instruments: Plasma-Cise ${ }^{\mathrm{TM}}$ and Plasma-Cut $^{\mathrm{TM}}$. 
Table 1 - Site and etiology of the stricture.

\begin{tabular}{lc}
\hline & N Patients (\%) \\
\hline Site & $22(81.5)$ \\
Urethra & $4(14.8)$ \\
$\quad$ Penile & $15(55.6)$ \\
Bulbar & $3(11.1)$ \\
$\quad$ Membranous & $5(18.5)$ \\
Bladder neck & \\
Etiology & $23(85.2)$ \\
Iatrogenic & $13(48.2)$ \\
$\quad$ TURP & $2(7.4)$ \\
TUR-BT & $3(11.1)$ \\
RP & $4(14.8)$ \\
RRP & $1(3.7)$ \\
Ileal neobladder & $4(14.8)$ \\
Traumatic & \\
\hline
\end{tabular}

$T U R P=$ transurethral resection of prostate; $T U R-B T=$ trans urethral resection of bladder tumor; $R P=$ retropubic simple prostatectomy; $R R P=$ retropubic radical prostatectomy.

All patients were evaluated preoperatively based on previous medical history, physical examination, urine culture, ultrasound of the upper tract, ure- thrography and uroflowmetry. Combined antegrade and retrograde urethrography was performed in two patients with previously placed suprapubic tube. Any active urinary tract infection was treated and routine prophylactic antibiotics were administered before surgery. All patients received general or spinal anesthesia. For safety purposes, a guidewire or $5 \mathrm{~F}$ ureteral catheter was passed through the stricture whenever possible (Figure-2). Core-through vaporization was performed for obliterative strictures in two patients with suprapubic tube. The procedure was performed by using a $19 \mathrm{~F}$ cystoscope and PlasmaKinetic ${ }^{\mathrm{TM}}$ cystoscope instruments were easily passed through the $5 \mathrm{~F}$ working channel of the cystoscope (Figure-1).

Vaporization was performed at 12 o'clock for urethral strictures and at 4 and 8 o'clock for bladder contractures using 60 watt vaporization power setting and $0.9 \%$ sodium chloride solution for irrigation. No desiccation was done. An 18 Fr. urethral catheter was left in the bladder for 24 hours after the procedure.

Uroflowmetry and urethrography were performed one month after surgery and repeated every 3 months. All patients were evaluated using urethroscopy 12 months after the procedure to assess the outcome. During the follow-up, if maximum flow rate (Q max) was $<15 \mathrm{~mL} / \mathrm{s}$, urethroscopy was performed to exclude recurrent stricture. The results
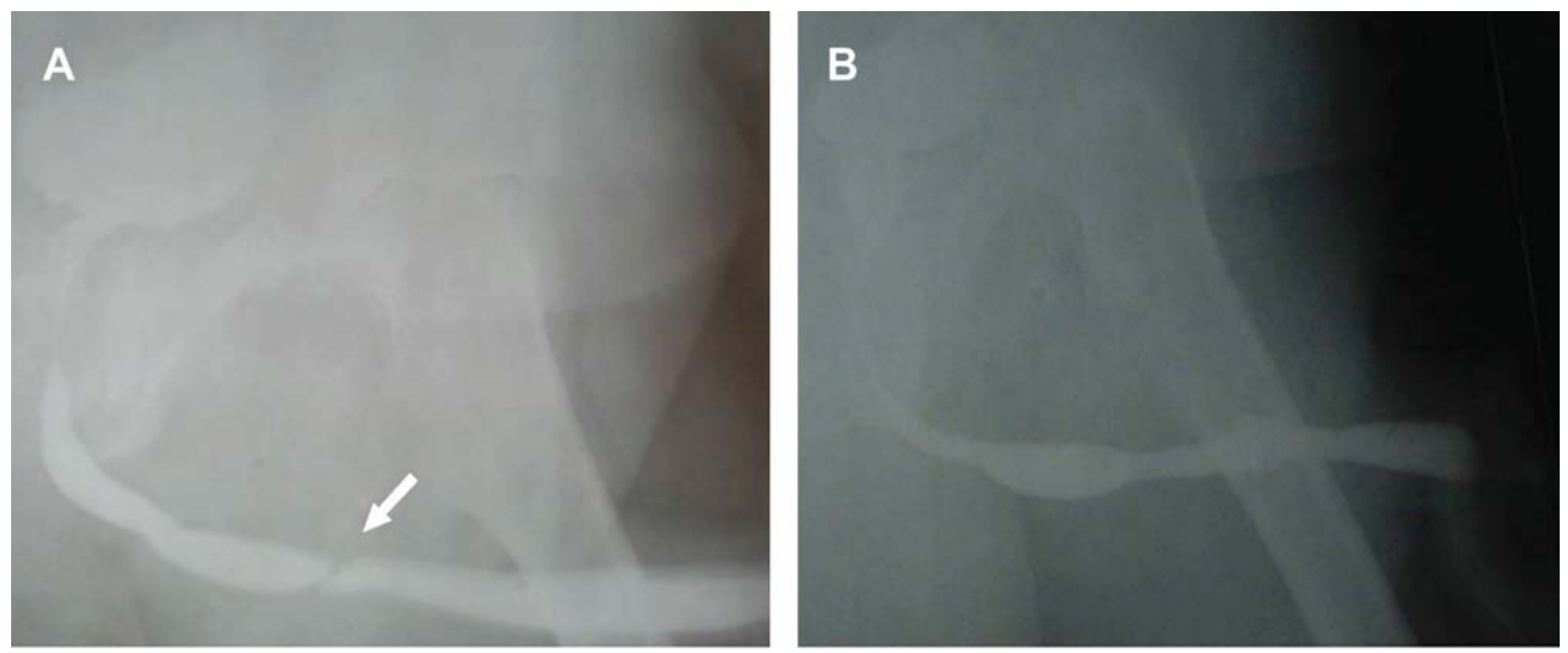

Figure 2 - A)- Preoperative urethrography showing urethral stricture (arrowhead). B)- Postoperative urethrography showing widely patent urethra after bipolar vaporization. 

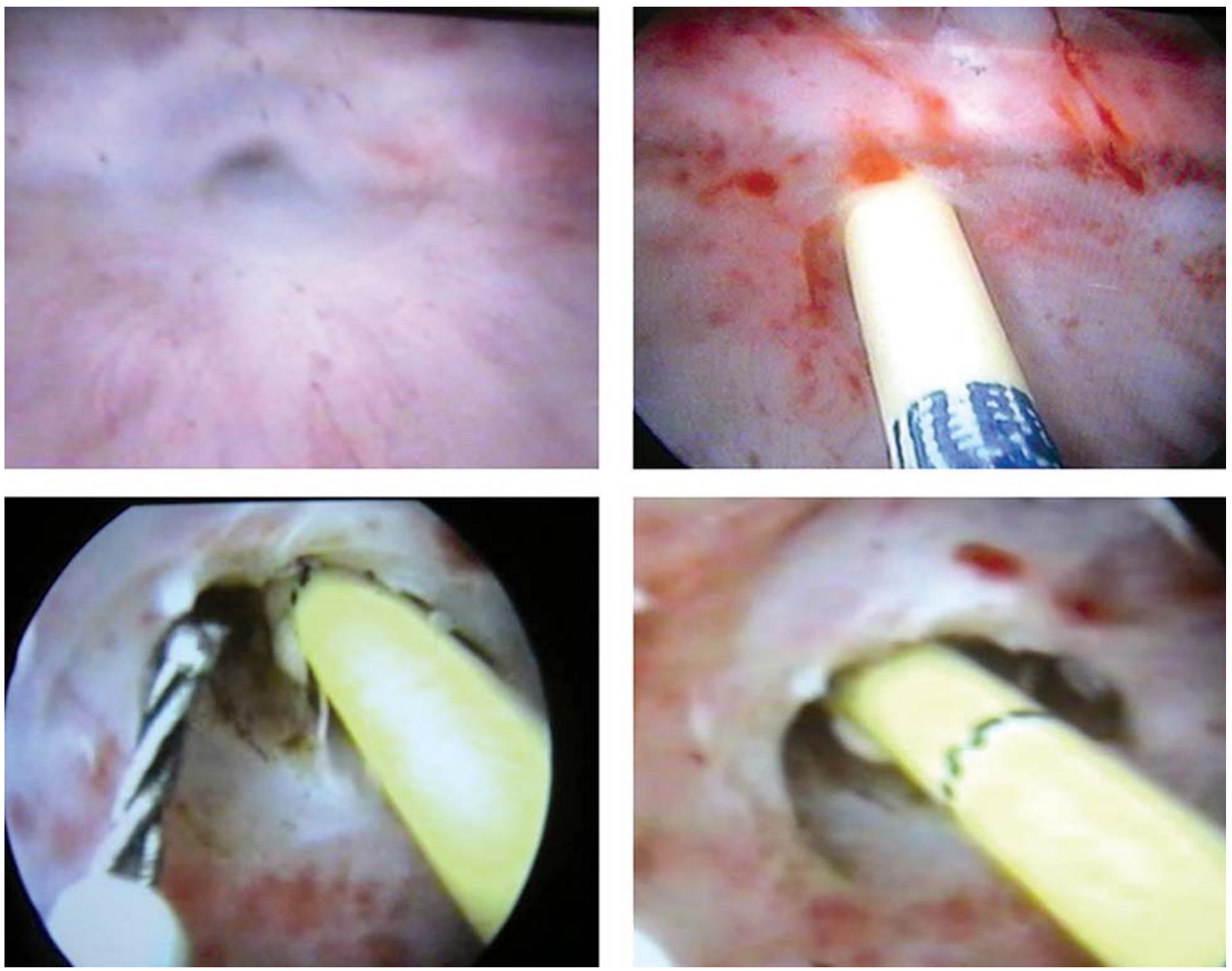

Figure 3-A guide-wire was passed through the stricture whenever possible and vaporization was performed.

were considered as "successful" in patients in whom the Q max was $\geq 15 \mathrm{~mL} / \mathrm{s}$ without any obstructive symptoms and with no evidence of recurrent stricture with urethrography or urethroscopy (Figure-3) (7). The outcome was defined as a "failure" if the patient needed any intervention after initial treatment due to re-stenosis (7). The follow-up was 12 to 20 months (mean 13.8 months). Preoperative mean Q max was $4.9 \mathrm{~mL} / \mathrm{s}$ (range 0 to 9 ) in 22 patients who had urethral stricture and $3.4 \mathrm{~mL} / \mathrm{s}$ (range 0 to 5 ) in 5 patients who had bladder neck contracture. The overall mean Q max was $4.6 \mathrm{~mL} / \mathrm{s}$ (range 0 to 9 ) before surgery in 27 patients.

Statistical analysis was carried-out using the NCSS-PASS 2007. Differences between the preopera- tive and postoperative mean $\mathrm{Q}$ max values of patients were analyzed by the Wilcoxon test. Differences were considered significant for $\mathrm{p}<0.05$.

\section{RESULTS}

In 25 patients, we passed a guidewire or 5 Fr. ureteral catheter without any technical difficulty. Core-through vaporization was applied in two cases with obliterative strictures, successfully. Blood loss was negligible and excellent visualization was maintained throughout the procedure. The average operative time was 15 minutes (range 8 to 30 ). All patients were continent after removing the catheter and able 
Bipolar Energy for Treating Urethral Strictures

Table 2 - Mean $Q$ max of patients that did not require a subsequent procedure depending on location of the stricture.

\begin{tabular}{lccc}
\hline Location & N Pts & Preoperative Q $\max$ & Postoperative Q max \\
\hline Urethra & 22 & $4.9 \mathrm{~mL} / \mathrm{s}$ & $14.9 \mathrm{~mL} / \mathrm{s}$ \\
Bladder neck & 5 & $3.4 \mathrm{~mL} / \mathrm{s}$ & $16.2 \mathrm{~mL} / \mathrm{s}$ \\
\hline
\end{tabular}

to void, satisfactorily. Postoperative Q max ranged between 6 to $25 \mathrm{~mL} / \mathrm{s}$ (mean $15.2 \mathrm{~mL} / \mathrm{s}$ ) in 27 patients. Twenty patients without any evidence of recurrence on urethrography voided with a mean Q max of 17.2 $\mathrm{mL} / \mathrm{s}$ (range 15 to 25 ) at the end of the first month.

In 22 patients with urethral stricture, at a mean follow-up time of 14.2 months (range 12 to 20 months) and the postoperative $\mathrm{Q}$ max ranged between 6 to $24 \mathrm{~mL} / \mathrm{s}$ (mean $14.9 \mathrm{~mL} / \mathrm{s})(\mathrm{p}<0.0001)$ (Table2). Seventeen of these patients with urethral stricture had no signs or symptoms to suggest recurrence after urethrography and uroflowmetry examinations, and the post-operative Q max ranged between 16 to 24 $\mathrm{mL} / \mathrm{s}$ (mean $16.8 \mathrm{~mL} / \mathrm{s}$ ). Recurrent stricture was found in $5(22.7 \%)$ cases, 3 of which underwent urethroplasty (Q max was $6 \mathrm{~mL} / \mathrm{s}$ in all cases) and 2 were on urethral dilation (Table-3). The Q max was $11 \mathrm{~mL} / \mathrm{s}$ and $13 \mathrm{~mL} / \mathrm{s}$ in two patients who required urethral dilation. After urethral dilation, the $\mathrm{Q} \max$ of these patients was improved to $15 \mathrm{~mL} / \mathrm{s}$ and 17 $\mathrm{mL} / \mathrm{s}$, respectively. In all 5 patients, urethroscopy was performed to confirm recurrent urethral stricture. We had no evidence of voiding dysfunction in these patients, and therefore we did not use urodynamic study in the evaluation.

Of the 5 cases with bladder neck contracture, 3 were cured with a mean follow-up time of 12.2 months (range 12 to 14 ). The mean Q max was 16.2 $\mathrm{mL} / \mathrm{s}$ (range 7 to 25$)$, postoperatively $(\mathrm{p}=0.043)(\mathrm{Ta}-$ ble-2). One patient with a $\mathrm{Q} \max$ of $7 \mathrm{~mL} / \mathrm{s}$ required a second vaporization of the contracture and the other improved with frequent urethral dilation (Q max was increased from $10 \mathrm{~mL} / \mathrm{s}$ to $17 \mathrm{~mL} / \mathrm{s}$ ) (Table-3).

The success rate was $77.3 \%(17 / 22)$ for urethral stricture and $60 \%(3 / 5)$ for bladder neck contracture. A total of 20 out of 27 patients were cured

Table 3 - Outcome of bipolar vaporization and subsequent procedures.

\begin{tabular}{|c|c|c|c|c|c|c|}
\hline & \multirow{2}{*}{$\begin{array}{l}\text { N } \\
\text { Pts }\end{array}$} & \multirow{2}{*}{$\begin{array}{l}\quad \mathbf{N}(\%) \\
\text { Pts Without } \\
\text { Recurrence }\end{array}$} & \multirow{2}{*}{$\begin{array}{c}\mathbf{N}(\%) \\
\text { Pts With } \\
\text { Recurrence }\end{array}$} & \multicolumn{3}{|c|}{ N Pts With Subsequent Procedures } \\
\hline & & & & Urethroplasty & Dilation & Vaporization \\
\hline \multicolumn{7}{|l|}{ Site } \\
\hline Urethra & 22 & $17(77.3)$ & $5(22.7)$ & 3 & 2 & \\
\hline Bladder neck & 5 & $3(60)$ & $2(40)$ & & 1 & 1 \\
\hline \multicolumn{7}{|l|}{ Etiology } \\
\hline Iatrogenic & 23 & $18(78.3)$ & $5(21.7)$ & & & \\
\hline TURP & 13 & $11(84.6)$ & $2(15.4)$ & 1 & 1 & \\
\hline $\begin{array}{l}\text { TUR-BT } \\
\text { RP }\end{array}$ & $\begin{array}{l}2 \\
3\end{array}$ & $\begin{array}{l}2(100) \\
2(66.7)\end{array}$ & $1(33.3)$ & & 1 & \\
\hline RRP & 4 & $2(50)$ & $2(50)$ & & & 1 \\
\hline Ileal neobladder & 1 & $1(100)$ & & & 1 & \\
\hline Traumatic & 4 & $2(50)$ & $2(50)$ & 2 & & \\
\hline
\end{tabular}

$T U R P=$ transurethral resection of prostate; $T U R-B T=$ transurethral resection of bladder tumor; $R P=$ retropubic simple prostatectomy; $R R P=$ retropubic radical prostatectomy. 
(74\%) after the procedure during a mean follow-up of 13.8 months (range 12 to 20 months).

\section{COMMENTS}

Iatrogenic causes, which result in strictures anywhere in the urethra, are the most common cause in current clinical practice and the optimal management still remains widely debated. Though urethroplasty has a high success rate, endoscopic treatment is still preferred by the majority of urologists (74\%) because of its safety and simplicity $(2,8-10)$.

The low success rates of cold knife urethrotomy prompted us to search for different therapeutic alternatives, and various types of lasers were attempted for this purpose. The reason for using lasers instead of cold knife depends on the basis of decreased formation of scar tissue. Primary experience with lasers have shown success rates ranging between $36 \%$ and $50 \%$. Some of the recent reported studies have shown promising success rates of up to $93 \%$ with contact Nd: YAG laser and Ho:YAG laser $(1,11,12)$. Because of its high cost, laser treatments have not gained wide popularity for routine use. Therefore, we conducted this study to confirm if the vaporization could be an alternative energy source for the treatment of urethral strictures and bladder neck contractures.

The intended use of bipolar vaporization using PlasmaKinetic ${ }^{\mathrm{TM}}$ cystoscope instruments is to perform vaporization of fibrous tissue. Two types of tip design are available; braided-tip (Plasma-Cut ${ }^{\mathrm{TM}}$ ) for finer fibrous tissue, and spring-tip (Plasma-Cise ${ }^{\mathrm{TM}}$ ) for more aggressive fibrous tissue removal in stricture or bladder neck incisions. The mechanism of the bipolar energy depends on a vapor ball that is located around the end of the device where energy is passed. The high-frequency energy passes through the $0.9 \%$ sodium chloride solution that is in contact with the scar tissue from the active to the return tip of the instrument. The irrigation solution forms a thin layer to convert into vapor plasma containing energy charged particles. When these high energy charged particles come in contact with the tissue, they cause disintegration through molecular dissociation $(4-6,13,14)$. This leads to lower temperatures at the treatment site, so that the depth of the thermal damage of the surrounding tissue is less than $1 \mathrm{~mm}$. In recent studies, the depths of the vaporization ranged from $118 \mu \mathrm{m}$ to $163 \mu \mathrm{m}$ compared with $287 \mu \mathrm{m}$ for the monopolar energy $(4,15)$. The depth of penetration of Ho:YAG laser, which is known to be as shallow, is $0.5 \mathrm{~mm}(11,16)$.

The main difference between the bipolar energy and cold-knife procedures is that the fibrotic tissue is not only incised but also evaporated with the vaporization. Thus, the recurrence of scar tissue can be decreased (4-6,15). As in laser therapy, we observed that the tissue removal was rapid and bleeding was minimal with the vaporization, and surgical field was visually clearer than the cold knife urethrotomy.

However, the abundant corpus spongiosum around the bulbar urethra renders endoscopic treatment more successful than the bladder neck, coldknife urethrotomy is limited for short strictures in the bulbar urethra. This technique has high failure rates especially when the stricture is longer or is associated with significant spongiofibrosis. As a common concept, urethroplasty is the ideal first-line therapy in younger patients with traumatic strictures $(8,10)$. We believe that bipolar vaporization can be considered an alternative treatment before performing more invasive procedure such as urethroplasty in older patients, the majority of which with longer and fibrotic iatrogenic urethral strictures and bladder neck strictures. If the bipolar technique is eventually selected in order to achieve lower rates of spongiofibrosis, bipolar vaporization can also be used effectively in younger patients with short traumatic strictures in the bulbar urethra.

The success rates of cold-knife urethrotomy at 5 years is less than that of urethroplasty ( $50 \%$ vs. $83 \%$ ) and it is well accepted that bipolar PlasmaKinetic $^{\mathrm{TM}}$ technology has a slightly greater failure rate compared with urethroplasty $(9,17)$. However, failure of the procedure does not affect a second repeated procedure. Indeed, this technique was successful in $77.3 \%$ of patients and spared the cases from a far more invasive procedure such as urethroplasty. Nevertheless, we believe that if vaporization fails, repeat attempts at endoscopic correction of urethral stricture should be abandoned in favor of definitive urethroplasty.

The results of core-through urethrotomy have ranged from $58 \%$ to $100 \%$ as reported by various investigators. A high recurrence rate (40\% to $50 \%)$ 
has been a cause of concern, especially after the use of cold knife $(16,18)$. The key to successful treatment of obliterative urethral strictures is not only to incise the hard fibrotic tissue but also to excise the fibrosis to prevent re-stenosis. For this reason, bipolar energy can be used to incise, excise and vaporize during the core-through procedure, lowering the risk of rescarring and re-stenosis by eliminating the need for coagulation (4-6).

In current study, we reported the first clinical experience with bipolar energy and our cure rate was $77.3 \%$ for urethral stricture and $60 \%$ for bladder neck contracture. As we compare success rates of bipolar energy with cold knife urethrotomy (range $60 \%$ to $70 \%$ ) and laser therapy (range $59 \%$ to $93 \%$ ) for the treatment of urethral strictures, our results seems to be as effective as laser treatment, and better than cold knife $(1,19,20)$. Furthermore, as regards the cost-effectiveness of the treatment, vaporization of the scarred tissue using bipolar energy by PlasmaKinetic ${ }^{\mathrm{TM}}$ cystoscopic instruments has an obvious advantage over laser therapies with good results for urethral strictures and bladder neck contractures.

There may be some limitations of this study, such as the inadequacy of the sample size, the lack of a questionnaire for the assessment of urinary symptoms, and the heterogeneity of the patients.

\section{CONCLUSION}

In the present study, short operative time, minimal surgical morbidity, negligible blood loss and satisfactory success rate cast new light on the endoscopic treatment of urethral stricture. Our results indicate that bipolar vaporization of urethral strictures is a safe and cost-effective procedure.

\section{CONFLICT OF INTEREST}

None declared.

\section{REFERENCES}

1. Kamal BA: The use of the diode laser for treating urethral strictures. BJU Int. 2001; 87: 831-3.
2. Peterson AC, Webster GD: Management of urethral stricture disease: developing options for surgical intervention. BJU Int. 2004; 94: 971-6.

3. Bullock TL, Brandes SB: Adult anterior urethral strictures: a national practice patterns survey of board certified urologists in the United States. J Urol. 2007; 177: 685-90.

4. Rassweiler J, Schulze M, Stock C, Teber D, De La Rosette J: Bipolar transurethral resection of the prostate--technical modifications and early clinical experience. Minim Invasive Ther Allied Technol. 2007; 16: 11-21.

5. Alschibaja M, May F, Treiber U, Paul R, Hartung R: Recent improvements in transurethral high-frequency electrosurgery of the prostate. BJU Int. 2006; 97: 243-6.

6. Smith D, Khoubehi B, Patel A: Bipolar electrosurgery for benign prostatic hyperplasia: transurethral electrovaporization and resection of the prostate. Curr Opin Urol. 2005; 15: 95-100.

7. Micheli E, Ranieri A, Peracchia G, Lembo A: End-toend urethroplasty: long-term results. BJU Int. 2002; 90: 68-71

8. Greenwell TJ, Castle C, Andrich DE, MacDonald JT, Nicol DL, Mundy AR: Repeat urethrotomy and dilation for the treatment of urethral stricture are neither clinically effective nor cost-effective. J Urol. 2004; 172: 275-7.

9. Mandhani A, Chaudhury H, Kapoor R, Srivastava A, Dubey D, Kumar A: Can outcome of internal urethrotomy for short segment bulbar urethral stricture be predicted? J Urol. 2005; 173: 1595-7.

10. Rourke KF, Jordan GH: Primary urethral reconstruction: the cost minimized approach to the bulbous urethral stricture. J Urol. 2005; 173: 1206-10.

11. Matsuoka K, Inoue M, Iida S, Tomiyasu K, Noda S: Endoscopic antegrade laser incision in the treatment of urethral stricture. Urology. 2002; 60: 968-72.

12. Perkash I: Ablation of urethral strictures using contact chisel crystal firing neodymium: YAG laser. J Urol. 1997; 157: 809-13.

13. Eaton AC, Francis RN: The provision of transurethral prostatectomy on a day-case basis using bipolar plasma kinetic technology. BJU Int. 2002; 89: 534-7.

14. Starkman JS, Santucci RA: Comparison of bipolar transurethral resection of the prostate with standard transurethral prostatectomy: shorter stay, earlier catheter removal and fewer complications. BJU Int. 2005; 95: 69-71.

15. Wendt-Nordahl G, Häcker A, Reich $\mathrm{O}$, Djavan B, Alken P, Michel MS: The Vista system: a new bipolar resection device for endourological procedures: 
comparison with conventional resectoscope. Eur Urol. 2004; 46: 586-90.

16. Dogra PN, Nabi G: Core-through urethrotomy using the neodymium: YAG laser for obliterative urethral strictures after traumatic urethral disruption and/or distraction defects: long-term outcome. J Urol. 2002; 167: 543-6.

17. Barbagli G, Palminteri E, Bartoletti R, Selli C, Rizzo $\mathrm{M}$ : Long-term results of anterior and posterior urethroplasty with actuarial evaluation of the success rates. J Urol. 1997; 158: 1380-2.
18. Thomas MA, Ong AM, Pinto PA, Rha KH, Jarrett TW: Management of obliterated urinary segments using a laser fiber for access. J Urol. 2003; 169: 2284-6.

19. Pansadoro V, Emiliozzi P: Internal urethrotomy in the management of anterior urethral strictures: long-term followup. J Urol. 1996; 156: 73-5.

20. Albers P, Fichtner J, Brühl P, Müller SC: Long-term results of internal urethrotomy. J Urol. 1996; 156: 1611-4.

\author{
Correspondence address: \\ Dr. Asif Yildirim \\ Hamidiye Mah, Barisyolu sok \\ Dumankaya Cekmekoy Evleri, A6/20, Cekmekoy \\ Umraniye, 34782, Istanbul, Turkey \\ Fax: + $90216372-5271$ \\ E-mail: asifyildirim@yahoo.com
}

\section{EDITORIAL COMMENT}

This study reminds us that the field of bipolar energy is moving forward and wider to treat urethral strictures besides transurethral resection of prostate. The endoscopic technology in the 21st century is running, not walking, towards reduction in the use of irrigation volume, bleeding, catheter, and hospital time. Urologist should not be left behind while the winds of endoscopy are blowing.

A limitation of this study is the small number of patients recruited at its current status. This limitation greatly implicates the interpretation of the complication findings. The use of statistics to decide clinical relevance of these findings at this stage is premature; hence, they must be viewed cautiously. Their statistical significance or insignificance may not reflect a true clinical relevance. A double-blind randomized comparison and accrual of a larger pool of patients with a longer follow-up period will definitely provide a more accurate picture that may prove the difference between bipolar energy, cold knife urethrotomy and laser therapy. More data will be needed for the comparison of different devices and for the further assessment of complications.

Dr. A. Abou-Elela Urology Department, Cairo University Nasr City, Cairo, Egypt E-mail:ashrafaboelela@yahoo.co.uk 


\section{EDITORIAL COMMENT}

In this issue of International Braz J Urol, Basok and co-workers report their preliminary experience in the treatment of urethral stricture and bladder neck contracture using bipolar energy by PlasmaKinetic ${ }^{\mathrm{TM}}$ cystoscope instruments. They enrolled 22 male patients with urethral stricture and 5 with bladder neck contracture. In 22 patients with urethral stricture, postoperative mean $\mathrm{Q}_{\max }$ was 14.9 $\mathrm{mL} / \mathrm{s}$ and the success rate was $77.3 \%$ at mean followup time of 14.2; in the 5 cases with bladder neck contracture, the success rate was $60 \%$ with a mean $\mathrm{Q}_{\max }$ of $16.2 \mathrm{~mL} / \mathrm{s}$ at a mean follow-up time of 12.2 months. Authors conclude that bipolar vaporization is a safe, inexpensive and reliable procedure with good results, minimal surgical morbidity and negligible blood loss. They suggest that this new technique can be considered favorably as a new therapeutic option for the endoscopic treatment of urethral stricture and bladder neck contracture.

Each new technique is thought to be better than the old one, but it can be asserted only after a well design study with an adequate follow-up. Unlike new drugs, such as antimuscarinic agents or botulinum toxin for the treatment of overactive bladder, which require a substantial amount of research and assessment before licensing, new surgical procedures have often found their way into clinical practice with little and imperfect evidence. This has also been the case in Urology. Examples may be the widespread use of several and different sets of mid-urethral sling for the treatment of stress urinary incontinence or different techniques, using mesh, for pelvic organ prolapse repair. As concerns results, it generally seems that many of the new surgical approaches have not been developed gradually using adequate health-technology-assessment systems. This topic was primarily addressed by the Interventional Procedures Program of the UK's National Institute for Health and Clinical Excellence (NICE), which has published guidelines regarding the efficacy and safety of over 250 procedures since 2002. These guidelines primarily apply to the UK but are also used as a source of information for other countries (1).

Recently Barbagli and Lazzeri addressed the issue of performing randomized controlled studies on urethral reconstructive surgery (2). They realized that the evidence for new surgical techniques has often been poor, and typically included small numbers of patients with inadequate length and completeness of follow-up (3). The question is what has history taught us as regards who is dealing with new urethral reconstructive surgeries?

Most of the evidence usually comes from case series, whereas evidence from randomized trials is sparse and meta-analyses of these trials are extremely rare. One of the outstanding examples of that it is the introduction of oral mucosa as a substitute material. Currently, oral mucosa has become the most popular substitute material in the treatment of urethral strictures, as it is readily available and easily harvested from the cheek, lip or tongue, allowing for a concealed donor site scar with low oral morbidity (4). All the papers that have contributed to the widespread use of the oral mucosa graft are retrospective, not prospective, nor are they randomized, controlled trials.

Lack of good evidence for new techniques or new approaches to urethral strictures may represent challenges for many of us. It is a challenge for urologists who want to offer potential benefits of new treatments to suitably selected patients, for patients who need good information when making choices and for government and private health-care funding bodies in deciding whether new procedures should be introduced into use and reimbursed. Thus, caution should be reserved for any new techniques before introducing them in clinical practice. Registers for collection of data for all patients undergoing a new procedure might represent a valuable tool regarding efficacy and safety, when evidence from randomized trials is lacking.

\section{REFERENCES}

1. National Institute for Health and Clinical Excellence. Interventional procedures: issued guidance. 2007 http://www.nice.org.uk/guidance/index.jsp?action=b yType $\&$ type $=3 \&$ status $=3 \&$ bId $=\mathrm{t}$ (accessed May 12, 2008).

2. Barbagli G, Lazzeri M: Can Reconstructive Urethral Surgery Proceed Without Randomised Controlled Trials? Eur Urol. 2008; in press. 
3. Orandi A: One-stage urethroplasty. Br J Urol 1968;40: 717-9.
4. Cavalcanti A: Editorial comment on: Combined dorsal plus ventral double buccal mucosa graft in bulbar urethral reconstruction. Eur Urol. 2008; 53: 90.

Dr. Massimo Lazzeri

Department of Urology,

Casa di Cura Santa Chiara (GIOMI group)

Firenze, Italy

E-mail:lazzeri.m@tiscali.it 